\title{
Equador: revisitando o passado, justificando atitudes, construindo um herói
}

Gisélle Razera* $^{*}$

Resumo: O contato com a Literatura Contemporânea portuguesa possibilitou-me observar uma tendência dos escritores atuais em desenvolver narrativas de ficção usando como pano de fundo algumas passagens não ficcionais da história de Portugal. Em especial no Romance Equador de Miguel Sousa Tavares, a tentativa de reexplicar a dominação portuguesa em território africano, mesclando passagens de ficção com realidade pode ter sido uma tentativa de justificar atitudes políticas pretéritas do seu país natal, além de ser uma forma de construir um herói, ainda que sujeito ficcional. Usando como base teorias de Carlo Ginzburg sobre temas como choque cultural e exploração do homem pelo homem, e Edward Said sobre a colonização oriental, o presente trabalho apresenta como hipótese ser a distância a principal aliada de Tavares ao contar a sua versão da colonização lusitana com a pena da ficção: a distância temporal - que não possibilita ao leitor questionar as testemunhas desse ato, passado mais de um século; e a distância geográfico-cultural - que facilmente acostumou o nosso olhar, através da perspectiva européia, segundo Said, a aceitar a imagem do povo africano como exótico, e primitivo.

Palavras-chave: Literatura Portuguesa; Exploração; Colonialismo.
Abstract: Being in touch with the Portuguese Contemporary Literature has allowed me to observe a trend among current writers in developing fiction narratives with the use of certain non-fictional passages from Portugal's History in the background. Specifically, in Miguel Souza Tavares' novel, Equador, which portrays an effort to explain the Portuguese domination in the African territory, the combination of fiction and reality, may have been an attempt to justify past political decisions from his home country, in addition to representing a formula for building a hero, though a fictional character. Based on Edward Said's theories on Eastern colonization and on Carlo Ginzburg's ones on issues like cultural clash and the exploitation of men by men, the present work offers as an hypothesis that Tavares employs distance as his main ally when telling, with the quill pen of fiction, his version of the Lusitanian colonization: the temporal distance - preventing the reader from questioning the witnesses to this act, over a century later; and the geographic and cultural distance - which easily accustomed our way of looking at the African people, through the European perspective, making us, according to Said, accept them as an exotic and primitive people.

Keywords: Portuguese Literature, Exploitation, Colonialism

Não construas estátuas aos vossos heróis, é melhor erguer estátuas às vossas vítimas.

Jean de La Bruyère

\section{Introdução}

\footnotetext{
* Mestranda em Literatura Comparada na UFRGS, especialista em Literatura pela União Dinâmica de Faculdades Cataratas e Graduada em Letras Português-Inglês na mesma instituição.
} 
Ao ler livros de Literatura Portuguesa Contemporânea, em especial o romance de Miguel Sousa Tavares - Equador - algumas questões ficavam em aberto: Por que, um jornalista historiador por vocação, resolveu investigar os últimos anos da monarquia lusitana? E ainda: Qual seria a sua pretensão ao recontar, com a pena da ficção, fatos históricos importantes a Portugal?

Não se tem aqui a pretensão de responder taxativamente às questões mencionadas, e sim apresentar hipóteses, influenciadas principalmente por textos de Carlo Ginzburg, renomado historiador italiano, que em seu livro Olhos de Madeira, aborda temas como choque cultural e exploração do homem pelo homem, assuntos presentes no enredo de Equador.

A linha de pensamento de Ginzburg (2001) direciona suas conclusões ao seu ceticismo: segundo o italiano, a potência destrutiva do homem tem prevalecido sobre o seu senso moral, e a temática da exploração territorial européia em territórios africanos e asiáticos, sempre destrutiva, particularmente no caso de Equador, leva o leitor atento a refletir sobre a maneira e os motivos possíveis que levaram portugueses a colonizarem terras tão longínquas à sua terra natal.

\section{Hipóteses}

Há muitas hipóteses para explicar o interesse de escritores, como Miguel Sousa Tavares, em recontar passagens históricas dos seus países, com o álibi da ficção. No caso de Portugal, muito se menciona sobre uma tentativa de auto-afirmação nacional através da exaltação dos feitos pretéritos e uma nostalgia inerente ao que se refere àquele país ter sido um império transcontinental e em seguida tornar-se uma nação economicamente inexpressiva.

É sabido que a construção e manutenção de um império exigem, não raro, o sacrifício de outros povos - ou daqueles que, mesmo pertencendo a um mesmo povo, são considerados inferiores em relação aos que detém o poder. Falando-se somente daquilo que se entende como ocidente, para exemplificar, é possível mencionar o império romano, em relação aos gregos, o massacre espanhol aos incas, maias e astecas com a chegada das tropas de Pizarro em terras sul-americanas, e a exploração territorial e populacional portuguesa, em terras indianas, sul-americanas, e, finalmente, no território africano, palco do romance em questão.

O romance - Equador - tem como protagonista Luís Bernardo de Valença, homem do Direito da Faculdade de Coimbra (Portugal), solteiro por convicção, vaidoso e, medíocre, conforme a sugestão do narrador: 


\begin{abstract}
A sua qualidade era não alimentar demasiadas ambições, o seu defeito, o de não alimentar, provavelmente, ambição alguma. [...] reconhecia, sem excesso de vaidade que estava a vários planos acima do meio da sua frequiência: era mais bem educado do que os imediatamente abaixo, mais inteligente e culto, menos fútil do que os de cima.
\end{abstract}

TAVARES (2003, p. 17)

O desenvolvimento do romance consiste basicamente no acompanhamento da vida de Luís Bernardo, desde pouco antes de ele ter sido nomeado governador de S. Tomé e Príncipe, pequena colônia portuguesa na costa africana, terras nas quais estão centralizadas as passagens do livro.

Luís Bernardo era homem contraditório - para questões ligadas à sexualidade, normalmente agia com leviandade, enquanto que, na condição de chefe de Estado, defendia seus trabalhadores (negros que labutavam em condições sub-humanas) das injustiças que os exploradores conterrâneos lhes impunham - viveu um quotidiano de intenso trabalho nas ilhas africanas. Visitava as plantações, buscava conhecer a realidade dos habitantes nativos do local e demonstrava inclinação humanitária nas atitudes de governo. Nas horas vagas, seduzia mulheres, e não as assumia.

Sua missão era liderar a região mantida em um modelo de trabalho que oficialmente não era chamado escravidão e atender às missões diplomáticas dignas de um chefe de Estado, como, por exemplo, receber a visita em caráter de auditoria feita por um cônsul inglês, mais especificamente, um casal composto por David e Ann. Ele, político com uma imagem a reconstruir após uma missão mal sucedida na Índia, e ela uma loura que exalava sua libido pelos poros.

As ilhas de São Tomé e Príncipe foram o cenário em que no romance se trouxe à tona a discussão sobre a dominação portuguesa no território.

Contando com três pontos de vista mais específicos: o do narrador, que tenta ser imparcial e, a meu ver, sugere ser a tentativa mediadora do autor; o bom homem português, personificado em Luís Bernardo e o ponto de vista inglês, representado principalmente em David e Lord Cruzon, conforme abaixo, na voz de Cruzon:

[...] S. Tomé e Príncipe são duas ilhotas dos portugueses, situadas algures bem ao largo da costa ocidental de África. Julgo que tem uns trinta mil habitantes, dos quais um por cento são esclavagistas brancos e noventa e nove por cento de escravos negros, mantidos a chicote e pão e água. E, além disso, tem o pior clima do planeta e toda espécie de doenças que você possa imaginar.

TAVARES (2003, p. 274) 
A missão inglesa não era de caráter humanitário, mas econômico. Havia, de fato, na época, um tratado que exigia a extinção da exploração escrava humana na África pelo homem português, porque a ausência de custos em mão-de-obra escrava resultava no que os ingleses chamavam de concorrência desleal, conforme, conteúdo do diálogo abaixo:

- Perdoe a interrupção, Sir, mas para que quer o ministério um cônsul aí?
- Para garantir, ao abrigo de um tratado qualquer, que os portugueses acabem com o seu
mercado de escravos local que, ao que parece, faz concorrência desleal às nossas exportações
daquela zona de África. É uma espécie de polícia que queremos mandar para lá [...]. TAVARES (2003, p. 275)

Na representação portuguesa havia contradição: Luís Bernardo era anti-escravagista, tendo inclusive publicado o seu ponto de vista em imprensa de Portugal; enquanto que é possível sugerir que o império português não se opunha (oficialmente) à exploração do homem pelo homem - no caso, o branco português sobre o negro africano, ainda que nos discursos se dissimulasse o contrário:

- Se bem percebi o que Vossa Majestade me disse, existe, de facto, uma forma de trabalho escravo em S. Tomé. E o que se espera do novo governador é que isso não seja visível aos olhos do inglês, de maneira a não nos expor a represálias do nosso famigerado aliado. Mas, ao mesmo tempo, espera-se que nada de essencial seja mudado, de modo a não comprometer o funcionamento da economia local.

- Não, não é isso. Nós abolimos oficialmente a escravatura há muito tempo, e temos uma lei, datada de dois anos, que estabelece as regras para o trabalho contratado nas colônias e cujo regime não tem nada a ver com escravatura. Desejo que isto fique bem claro: Portugal não pratica nem consente escravatura nas colônias.

TAVARES (2003, p. 62)

Há no romance uma distância entre o dito na metrópole e o praticado nas colônias, como visto em várias passagens, nas atitudes de alguns dos seus assessores nas ilhas.

A estada de Luís Bernardo em ilhas africanas tornou-se uma luta constante em garantir uma qualidade de vida humanamente decente aos trabalhadores ilhéus, dentro do que era possível - e governar aquelas ilhas com o pulso dos seus ideais anti-escravagistas.

$\mathrm{O}$ enredo do romance é permeado pelo envolvimento afetivo-sexual entre Luis Bernardo e Ann, a sensual esposa do cônsul inglês. Entregue à paixão, solitário, sem companhias confiáveis naquelas terras tão quentes, Bernardo foi vencido pela paixão humana.

Naquele ambiente pluralmente hostil, cercado por rivais - tendo vindo à superfície suas falhas de caráter (adultério) e a traição patriótica do ato, encurralado pelos próprios atos incorretos, - o desfecho do romance se dá com o seu suicídio.

Diante de todo esse cenário: intrigas políticas, paixões humanas, interesses políticointernacionais há uma questão que vale a pena refletir: um português, Miguel Sousa Tavares, escreve um romance baseado em estudo de documentos históricos descortinando, 
supostamente, a escravatura portuguesa na África, nos fins da monarquia lusitana. Chama atenção, o que a mim parece uma sutil maneira de justificar a atitude portuguesa no que seria também um erro inglês:

[...] Desejo que isso fique bem claro; Portugal não pratica nem consente escravatura nas suas colônias. Isso é uma coisa; outra coisa é submetermo-nos ao que os ingleses, e não por razões primeiramente altruístas, querem achar que é escravatura e que para nós não passa de formas de trabalho recrutado, segundo hábitos locais, e que não têm necessariamente de coincidir com o que se faz na Europa. Ou alguém acredita, por exemplo, que um inglês trata os seus criados na Índia como os trata em Inglaterra?

TAVARES (2003, p. 62)

De certa forma, é como se afirmasse que Portugal não escravizava os africanos, ele submetia-os a um regime de trabalho culturalmente aceito em seus territórios e não aceito na Europa por não haver na cultura daquele continente modelo de trabalho semelhante.

Além disso, a justificativa estaria em mencionar a hipótese de os ingleses não agirem em territórios por eles dominados na Índia com o mesmo altruísmo exigido dos portugueses, no caso de S. Tomé e Príncipe.

Contando também que quando descreve a situação de Portugal naquele contexto, não economiza em descrever o suposto sofrimento da população lusa - assim, atenuando a exploração dos africanos como sendo uma tentativa de tirar a população lusitana de uma difícil condição de vida:

[...] E, embora Luís Bernardo fosse um monárquico condescendente - mais por herança familiar do que por convicção assumida - certos argumentos dos republicanos pareciam-lhe carregados de razão. Desde 1890 - a data do ultimatum inglês - o país mergulhara em profunda crise política, econômica, cultural, social. Com o fim da escravatura no Brasil, tinham cessado as remessas dos emigrantes, que até aí equilibravam as contas externas do reino. Tudo o que era imprescindível à modernização do país era importado, e as únicas verdadeiras exportações eram a cortiça e as conservas de peixe. Pequenos sectores, como o vinho do Porto ou o cacau de S. Tomé, eram uma pequeníssima contribuição no imenso déficit comercial corrente. Todos os anos, o orçamento apresentava um desequilíbrio de cinco a seis mil contos, a acumular a uma dívida flutuante de oitenta mil. Mais de três quartos da população de cinco milhões e meio de pessoas vivia nos campos, mas a agricultura, inteiramente baseada numa mão-de-obra barata e miserável, não chegava sequer para evitar a fome. Oitenta por cento da população era analfabeta, noventa por cento não dispunha de cuidados de saúde e vivia exposta à doença e às epidemias, basicamente como na Idade Média. Portugal era o mais atrasado país da Europa, o mais pobre, o mais triste. Mesmo entre a elite, pouco mais acontecia que as cíclicas revoltas dos estudantes de Coimbra contra os exames ou a temporada lírica do S.Carlos, que durava três meses de inverno e ponto final.

TAVARES (2003, p. 82)

Esta passagem, além de ser capaz de provocar uma sensibilização no leitor, no sentido de sugerir implicitamente que Portugal não cometia com a escravidão um ato ganancioso, pois, se explorava terras africanas era para, talvez, melhorar a condição de vida da sua miserável população - coloca em Portugal um quê de vítima, e despersonaliza o seu algoz, sendo ele um sistema de governo fracassado: a monarquia. 
$\mathrm{O}$ ato de afirmar que o modo utilizado pelos portugueses era culturalmente compatível com o modelo africano pode ser a estratégia comum, segundo Edward Said no livro Orientalismo, do "ocidental" em descrever o mundo distante, estrangeiro ou exótico pela perspectiva do homem branco europeu, e assim, justificar uma série de atos que, caso cometidos igualmente em seus pares, seria considerado uma barbárie.

Unida à tendência naturalizada de estigmatização do povo não europeu com o selo do exotismo e da inferioridade, a questão da distância facilita muito o trabalho do autor que pretende recontar um fato histórico cem anos após o ocorrido. E entende-se distância aqui tanto em sentido cronológico quanto geograficamente.

Nas últimas décadas a relação entre história, memória e esquecimento foi discutida muito mais intensamente do que no passado. Isso se deu, como tantos já disseram, em virtude de múltiplos motivos; o iminente desaparecimento físico da última geração de testemunhas do extermínio de judeus da Europa; o surgimento de novos e velhos nacionalismos na África, Ásia e Europa; a crescente insatisfação com respeito à história. (GINZBURG, 2001, p. 178).

A abordagem feita por Ginzburg focaliza-se no povo judeu, mas é aplicável às questões africanas. Se considerarmos os portugueses estando na condição de algozes e os africanos em condição de vítimas, a questão da distância cronológica facilita o ato de recontar a história da exploração portuguesa na África, pois os contemporâneos daquele período já não estão vivos para confirmarem ou retificarem as informações contidas no romance.

Essa conclusão, é óbvio, não se refere apenas à tradição judaica. Em qualquer cultura, a memória coletiva transmitida por ritos, cerimônias e eventos semelhantes, reforça um nexo com o passado que não pressupõe uma reflexão explícita sobre a distância que nos separa dele.

GINZBURG (2001, p. 179)

Além da exploração do trabalho, é sabido, ainda que não enfatizado no romance Equador, que a dominação européia na África também contou com uma culturalização do negro pelo branco. Com isso é provável que uma série de costumes que transmitiam a tradição africana tenham sido misturados ou até mesmo perdidos em virtude de o povo dominado internalizar a cultura externa, do seu dominador.

Outra questão pertinente em relação à distância está na questão geográfica: a dificuldade de acesso àquelas terras africanas, a morosidade e precariedade do transporte marítimo e o desconforto comum nos navios e nas más condições de hospedagem das ilhas, não faziam daquele território um destino turístico comum. Como é mencionado no livro de Tavares, praticamente só pisavam naquele solo os políticos com missões para serem executadas naquele local e os exploradores europeus da região. 
Parece claro afirmar que a ótica dessas pessoas em relação ao povo africano era a de que eram homens passíveis de serem explorados, pois, a dita raça negra era considerada inferior à branca européia, idéia vigente na época do romance.

Este afastamento geográfico dificultou que olhos diferentes observassem as ilhas africanas e nos trouxessem relatos não viciados no ranço escravocrata. O que pode ter privado os estudiosos atuais de contato com documentos e relatos verossímeis sobre o modo como se explorava os africanos, inclusive Tavares.

Esta incomunicabilidade patrocinada pelo difícil acesso pode ter sido aliada dos portugueses em cometer atos atrozes no povo da África. Além disso, por mais que a população européia fosse consciente do modelo exploratório na época, atitudes portuguesas tomadas longe das vistas portuguesas, em locais remotos, parecia não afetar emocionalmente as pessoas.

Nesse cenário, um evento a milhas de distância: a exploração de um povo considerado sub-humano, praticada pelo bem de um país europeu (onde viviam pessoas civilizadas, de raça privilegiada) não era considerado um ato imoral. Segundo Ginzburg, esta ideia relacionada à distância já era debatida em textos de Diderot:

[...] Concordamos em que a distância em relação aos lugares e ao tempo talvez atenue mais ou menos todos os sentimentos, toda sorte de consciência, mesmo a do crime. O assassino transportado para as terras da China está longe demais para perceber o cadáver que deixou sangrando na beira do Sena. O remorso talvez nasça menos do horror de si do que do medo dos outros; menos da vergonha da ação do que da censura e do castigo que surgiriam se ela fosse descoberta.

GINZBURG (2001, p. 204).

Um século depois do período em que se passa o romance, com a ausência tanto dos responsáveis pela exploração africana quanto das vítimas dos acontecimentos, além de uma série de estudos estarem corrente em meios acadêmicos, ora justificando os atos pretéritos, ora julgando-os e a impossibilidade de reviver a época devido à distância possibilitam que sejam trazidas à discussão o tema da escravidão, com uma aparente isenção da geração que a debate.

Entretanto, se há a necessidade de voltar a explicar a mesma história, talvez seja por um remorso latente e uma vontade implícita de se desculpar com a sociedade colonizada. Por que não considerarmos também um possível medo de que, na época de globalização e esclarecimento, diante da divulgação dos fatos, os povos vitimizados venham a exigir retratação por parte dos seus algozes, conforme acontece com a França e suas colônias. 


\section{Para aquilo que não há duvida, não são necessárias tantas explicações}

A perspectiva real jamais poderá ser revista. Conta-se a história para justificar atitudes pretéritas em condição de inviável checagem dos fatos: a geração que viveu aquele momento já não pode contar a sua versão (através da mesma perspectiva histórica); a geração que recebe esta literatura está distante geograficamente e cronologicamente; a pena da ficção é o álibi que liberta o escritor de qualquer possível equívoco - intencional ou não.

A barbárie da exploração portuguesa e das outras potências colonizadoras na África ocorreu muito longe dos olhares ocidentais e, como a distância pode anestesiar, foi possível e facilitado ao povo português manter-se indiferente à situação, seja por abstração ou ignorância. Contudo, os estudos culturais que marcam consideravelmente as linhas de pesquisa do século XXI questionam todo este processo exploratório fazendo uso de novos prismas.

Por uma provável necessidade de se explicar os motivos que fizeram os portugueses agirem como agiram - no caso de S. Tomé e Príncipe no romance Equador - com uma nuance atenuadora das ações é provável que tenha se tornado comum, em diversas literaturas - principalmente na européia, as releituras históricas como temas centrais dos livros de ficção.

Conforme já mencionado, a ficção absolve o escritor de equívocos conceituais, pois a liberdade poética lhe abre as portas para abordar o tema sem os grilhões da comprovação dos fatos.

É na ficção que o leitor se permite assimilar os assuntos sem a obrigatoriedade de classificar a informação em real ou ficcional. O texto literário é o modelo em que o leitor se permite não questionar com a mesma criticidade a veracidade dos fatos, o que não significa que não assimile o conteúdo e que não aprenda muito sobre o mundo real em cenários ditos irreais.

Esta combinação de distância - cronológica e geográfica, com a tendência não defensiva de uma leitura de ficção, combinada a uma maior abertura dos povos para debaterem questões tabus como a escravatura e a exploração dos povos, - além de uma possibilidade de novo entendimento não julgador, resultado de um amadurecimento social geral, é o que possibilita mexer em feridas sem o risco de piorá-las.

Com isso, cria-se um Luis Bernardo. Um homem idealista que foi em missão humanitária para um país distante, repleto de princípios elevados que sucumbiu à sua própria ingenuidade, ao tentar mudar uma realidade já pré-estabelecida: a escravidão. 
A abordagem de Tavares induz a se pensar que aquele pobre homem foi vítima de uma situação: governar um par de ilhas longínquas em nome do bem-estar do seu povo, ainda que não concordasse com o modo que lhe era imposto de agir.

\section{Referências}

GINZBURG, Carlo. Olhos de Madeira: Nove reflexões sobre a distância. São Paulo, 2001.

SAID, Edward W. Orientalismo: $O$ oriente como invenção do ocidente. São Paulo: Companhia de Bolso, 2008.

TAVARES, Miguel Sousa. Equador. Rio de Janeiro: Nova Fronteira, 2003. 